\title{
La ejemplaridad y proyección del precedente*
}

\author{
Exemplarity and Projection of Precedent
}

\author{
Sandra GómORA JUÁREz ${ }^{* *}$
}

\section{Resumen:}

En este artículo se propone un análisis descriptivo sobre las ideas de ejemplaridad y proyección como propiedades necesarias del concepto de precedente, entendiendo que los precedentes son reglas autoritarias en el contexto de un sistema jurídico. Además, se plantea la manera en que dichas propiedades funcionan y su distinción como elemento central en la práctica jurídica, sin los cuales el concepto de precedente no podría ser entendido apropiadamente.

\section{Palabras clave:}

Precedente, ejemplaridad, proyección, razones dependientes, razones excluyentes.

\begin{abstract}
:
The article claims for a descriptive analysis of precedent based on the ideas of exemplarity and projection as necessary properties, understanding the concept of precedent as authoritative rules in the context of a legal system. The author discusses the role of these properties and it's distinctiveness as central

Artículo recibido el 6 de abril de 2017 y aprobado para su publicación el 22 de agosto de 2017

** Investigadora en el Instituto de Investigaciones Jurídicas de la UNAM, sgo moraj@unam.mx; sitio institucional: https://www.juridicas.unam.mx/investigador/ perfil/sgomora.
\end{abstract}

D. R. C 2018. Universidad Nacional Autónoma de México-Instituto de Investigaciones Jurídicas Problema. Anuario de Filosofía y Teoría del Derecho, núm. 12, enero-diciembre de 2018, pp. 199-238 México, Ciudad de México, ISSN 2007-4387 
Esta revista forma parte del acervo de la Biblioteca Jurídica Virtual del Instituto de Investigaciones Jurídicas de la UNAM http://www.juridicas.unam.mx/

https://biblio.juridicas.unam.mx/bjv

https://revistas.juridicas.unam. mx/

SANDRA GÓMORA JUÁREZ

elements of the legal practice of judicial precedent, properties without which, the concept of precedent could not be properly understood.

\section{Keywords:}

Precedent, exemplarity, projection, dependent reasons, exclusionary reasons. 
SUMARIO: I. Introducción. II. Reglas comunicadas mediante el ejemplo. III. Buenos y malos ejemplos. IV. Sobre la propiedad de ejemplaridad y el recurso a la analogía. V. El ejemplo dotado de autoridad. VI. La regla de precedente como ejemplo autoritativo para la autoridad. VII. La proyección del precedente. VIII. Conclusiones. IX. Referencias bibliohemerográficas.

\section{INTRODUCCIÓN}

Las discusiones filosóficas en torno al precedente podrían ocuparse -en el plano normativo- de buscar la justificación de la práctica del precedente proponiendo cómo establecer, usar, interpretar, seguir, aplicar o expandir precedentes judiciales en el contexto de un sistema de precedentes real o imaginario. ${ }^{1}$ En tanto que -en el plano descriptivo- el análisis busca comprender mejor las instituciones, doctrinas y prácticas del precedente judicial, lo cual puede lograrse trabajando en un bagaje conceptual más preciso como resultado de una reconstrucción racional dentro de los límites conceptuales impuestos por la propia práctica, por ejemplo. ${ }^{2}$

1 Un ejemplo de teoría del precedente de este tipo es el trabajo de Thomas Bustamante que ofrece una "teoría genuinamente normativa de los precedentes judiciales... que pretende proporcionar parámetros metodológicos para establecer, con cierto grado de objetividad, «cómo hacer cosas con precedentes judiciales»...". Esta teoría (normativa o argumentativa) busca institucionalizar parámetros, reglas y procedimientos de argumentación que sirvan en la práctica de seguir precedentes judiciales, pero también para juzgar y evaluar la corrección de la aplicación de precedentes. Bustamante, Thomas, Teoría del precedente judicial. La justificación y la aplicación de reglas jurisprudenciales, trad. de Juan Carlos Panez Solórzano y Brian L. Ragas Solórzano, Lima, Editora y Distribuidora Ediciones Legales E. I. R. L., 2016, pp. 5-11.

2 Chiassoni, Pierluigi, "The Philosophy of Precedent: Conceptual Analysis and Rational Reconstruction", en Bustamante, Thomas y Bernal Pulido, Carlos (eds.), On the Philosophy of Precedent. Proceedings of the 24th World Congress of the International Association for Philosophy of Law and Social Philosophy, Beijing, 2009, Stuttgart, Franz Steiner Verlag, Nomos, vol. III, núm. suplementario 133, 2012, pp. 13-17. 
Concretamente, este trabajo se inscribe en el tipo de análisis conceptual que considera posible explicar la naturaleza ${ }^{3}$ de algunos objetos de estudio - el precedente en este caso- a través del análisis del concepto que explica dicho objeto. ${ }^{4}$ En otras palabras, este tipo de análisis sostiene que al explicar el concepto de un objeto determinado, estamos explicando la naturaleza de ese objeto. ${ }^{5}$

De acuerdo con la teoría clásica, el análisis del concepto debe explicar las condiciones que han de satisfacer los ejemplares del objeto de estudio, esto es, explicarnos qué características lo hacen ser eso que es, tarea que puede lograrse, por ejemplo, proporcionando las condiciones necesarias que revelen la naturaleza del objeto bajo estudio. ${ }^{6}$ El análisis del concepto implica efectuar el ejercicio de descomponer el concepto en los elementos que lo integran para revelar su estructura y características centrales. ${ }^{7}$

Dado que, en buena medida, las prácticas sociales determinan el contenido de algunos de nuestros conceptos, podemos decir que tenemos un concepto cuando esas prácticas son compartidas por una

3 La "naturaleza" de algo significa que ese objeto tiene propiedades esenciales que lo hacen ser lo que es cuando y donde sea que exista; eso significa que tales propiedades son universales y generales en tanto que son las propiedades que el objeto no fallará en tener en cualquier lugar; revelar esto significa revelar la naturaleza del objeto y se logra al explicar su concepto. Cuando se hace referencia a lo largo de este trabajo a la naturaleza del precedente, ésta debe ser entendida exclusivamente en los términos conceptuales planteados, y por consecuencia, queda establecido que este trabajo no tiene relación con cuestiones de carácter metafísico. Raz, Joseph, Between Authority and Interpretation. On the Theory of Law and Practical Reason, Nueva York, Oxford University Press, 2009, p. 25.

4 Este enfoque metodológico está presente en un sector importante de la filosofía del derecho y sigue generando importantes aportaciones a la disciplina. Véanse por ejemplo, los trabajos de H. L. A. Hart, Joseph Raz, Julie Dickson y Michael Giudice.

5 Ibidem, p. 24.

6 "Concepts", en The Internet Encyclopedia of Philosophy, http://www.iep.utm. edu/concepts/, 20 de junio de 2017.

7 Himma, Kenneth, "Reconsidering a Dogma: Conceptual Analysis, the Naturalistic Turn, and Legal Philosophy", Ross Harrison (ed.), Law and Philosophy. Current Legal Issues, Oxford, Oxford University Press, 2008, p. 4, disponible en: SSRN: https://ssrn.com/abstract=952910. 
comunidad respecto de cómo, cuándo y para qué usar un determinado término. ${ }^{8}$

En ese orden de ideas, en este artículo propongo un análisis descriptivo en torno a una de las que considero como propiedad necesaria del concepto de precedente, ${ }^{9}$ según la cual el precedente "tiene por objeto de regular mediante el ejemplo la conducta futura de sus destinatarios". Esta propiedad implica, a su vez, otras propiedades que revisaré brevemente para estar en condiciones de concentrarme en el análisis de la propiedad que aquí se propone.

\section{REGLAS COMUNICADAS MEDIANTE EL EJEMPLO}

En términos de la interrelación e implicación mutuas que muestran las propiedades necesarias del precedente, conviene advertir que parto de la tesis de que la mejor forma de explicar nuestro concepto de precedente es como una regla prescriptiva de origen jurisdiccional con calidad autoritativa. Si bien no me detendré en esta asunción, haré algún comentario al respecto para comprender la explicación siguiente.

Tomar la regla de la autoridad como una razón para actuar conforme que reemplaza las razones en las que se basó, es la forma adecuada de entender la autoridad legítima. ${ }^{10}$ Asumo entonces que el precedente es una regla autoritativa en sentido legítimo, ${ }^{11}$ esto es,

8 Ibidem, p. 6.

9 Por ahora, me refiero únicamente al precedente vertical en el que interviene una estructura de jerarquía judicial.

10 Raz, Joseph, The Morality of Freedom, Nueva York, Oxford University Press, 1986, p. 42.

11 La explicación conceptual de la autoridad del precedente se sustenta en las tres tesis de la autoridad legítima de Joseph Raz: $a$ ) la tesis de la dependencia; $b$ ) la tesis normal de justificación, y c) la tesis de la exclusividad. Raz, Joseph, La ética en el ámbito público, trad. de María Luz Melón, Barcelona, Gedisa, 2001, pp. 229 y 231; Giudice, Michael, “Joseph Raz's Legal Philosophy”, IVR Encyclopedie, 2009, pp. 2 y 3, consultado el 6 de abril de 2017 en: http://ivr-enc.info/index.php?title=Joseph_ Raz's_Legal_Philosophy, p. 3. 
que proporciona a sus destinatarios (tribunales y particulares, principalmente) razones para la acción al tiempo que excluye. ${ }^{12}$

El precedente es resultado de la labor cotidiana que desempeñan los tribunales al impartir justicia, misma que se desarrolla dentro de la estructura judicial establecida en un sistema jurídico. Esta estructura judicial implica una estructura jerárquica que permite establecer y delimitar competencias; de esta forma, gracias a la jerarquía, es posible delimitar e identificar qué tribunales y qué sentencias son las indicadas para sentar reglas con alcance más allá del caso concreto.

Debemos notar que al predicar de una regla autoritativa que es comunicada mediante el ejemplo, estamos distinguiendo esa regla de las demás reglas, es decir, dentro del sistema jurídico todas las reglas comparten una misma pretensión: el ser autoritativas, pero sólo algunas de ellas tienen además la misión de mostrarle a otros tribunales la forma en que se han de resolver casos similares.

Herbert Hart distinguió en El concepto de derecho dos recursos (como él los llamó) para comunicar pautas generales de conducta con antelación a las situaciones en que han de ser aplicadas: la legislación y el precedente. La legislación es una forma de comunicación de reglas mediante el lenguaje general, mientras que el precedente es una forma de comunicación de reglas mediante el ejemplo. ${ }^{13}$

Lo anterior significa que para desempeñarse como pauta de conducta, la regla tiene que existir antes de que se presente la situación de hecho; éste es un elemento muy característico de la legislación, ya que su aplicación es posible debido a que, generalmente, éstas se aplican a las situaciones que surgen con posterioridad a su en-

12 Una razón excluyente se define como una razón para no actuar con base en el balance de razones, una razón para no considerar las razones que intervendrían en el balance de razones de primer orden y para no actuar con base en ellas. Es importante tener presente que las razones excluyentes sólo eliminan la motivación de guiarse por las razones de primer orden (razones dependientes), mas no cancelan ni eliminan el actuar en correspondencia con ellas. Vega Gómez, Juan, "El positivismo excluyente de Raz", Boletín Mexicano de Derecho Comparado, nueva serie, año XXXVII, núm. 110, mayo-agosto de 2004, p. 713.

13 Hart, H. L. A., El concepto de derecho, trad. de Genaro R. Carrió, Buenos Aires, Abeledo-Perrot, 1961, pp. 155 y 157. 
trada en vigor; ${ }^{14}$ esto implica que la regla ha sido comunicada previamente mediante algún tipo de lenguaje explícito, por ejemplo, el lenguaje escrito.

Ciertamente, en un primer momento, la regla novedosa surge con posterioridad al hecho, es decir, gracias al planteamiento judicial de una situación conflictiva novedosa para el sistema jurídico para la que no existe una respuesta, a la que los tribunales tuvieron que dar solución, la cual, emanada del órgano jurisdiccional indicado, adquirió calidad autoritativa y fuerza vinculante.

De esta forma, la regla de precedente así establecida proporciona una respuesta al caso que le dio origen y del que surge por vez primera, así como también proporciona una respuesta anticipada a casos futuros semejantes que compartan rasgos relevantes. En ese sentido - una vez establecida-, la regla de precedente se aplica a futuro y comparte este rasgo con la legislación, porque surte también efectos a futuro, esto es, porque se estableció como regla con pretensión autoritativa con anticipación al surgimiento de los casos.

Las reglas de precedente sirven como ejemplo a subsecuentes tribunales para resolver asuntos de fondo similar y también como ejemplo a terceros para tomar decisiones acerca de su curso de acción cuando enfrenten problemas similares. Aunque el medio material para conocer el precedente es el lenguaje escrito, el contenido esencial de la regla que se pretende comunicar se transmite a través del ejemplo de lo que ciertos tribunales hacen en ciertos casos. El establecimiento de reglas a través del lenguaje escrito con anterioridad a su aplicación es propio de la legislación, mientras que el comportamiento de los tribunales en su labor jurisdiccional y la transmisión de reglas mediante el ejemplo es propio del precedente.

14 La excepción a esta normalidad es la retroactividad de las reglas, que permite en casos específicos que ciertas reglas tengan eficacia sobre actos sucedidos previamente a su expedición. Huerta Ochoa, Carla, "Retroactividad en la Constitución", El proceso constituyente mexicano. A 150 años de la Constitución de 1857 y 90 de la Constitución de 1917, México, UNAM, Instituto de Investigaciones Jurídicas, 2007, pp. 583, 584 y 587; Huerta Ochoa, Carla, "Sobre la validez temporal de las normas. La retroactividad y ultraactividad de las normas en el sistema jurídico", Problema. Anuario de Filosofía y Teoría del Derecho, núm. 1, 2007, pp. 267-304. 
Si aceptamos la afirmación de que el precedente es una forma de comunicación de reglas con pretensión autoritativa a través del ejemplo, entonces somos conscientes de que dicha afirmación tiene implícitas varias preguntas que es necesario desentrañar para comprender plenamente lo que eso significa para nosotros ordinaria y jurídicamente.

Evidentemente, como cualquier ejemplo y cualquier regla, las reglas de precedente llevan aparejada la carga de ser conocidas con anticipación al momento de recurrir a ellas, pues de otra forma, los sujetos a ella no estarían en condiciones de invocarlas, aplicarlas o ajustar su conducta al ejemplo. De esta manera, la publicidad acompaña al ejemplo y posibilita su exigibilidad.

\section{BUENOS Y MALOS EJEMPLOS}

Pensemos ahora en preguntas como ¿qué es un ejemplo?, ¿cuándo sucede que algo (digamos, una resolución judicial) es considerado como un buen ejemplo?, ¿qué es un ejemplo dotado de autoridad y qué es lo que le da autoridad a un ejemplo?, ¿por qué seguimos ejemplos dotados de autoridad y por qué los propios tribunales los siguen?, ¿quién o quiénes son los destinatarios del ejemplo dotado de autoridad?, ¿qué partes de la resolución judicial concretamente pueden servir como ejemplos autoritativos?

Las preguntas planteadas encierran, en conjunto, parte del contenido de la práctica que analizamos. Es muy probable que estas preguntas estén íntimamente relacionadas entre sí y que las respuestas que proporcionemos se impliquen entre sí, lo cual se hará evidente a lo largo de este trabajo.

Comencemos por preguntarnos ¿qué es un ejemplo? Comúnmente se entiende por "ejemplo" el hecho, acontecimiento o conducta pasada, que ya tuvo lugar, la cual posee algún valor intrínseco o relevancia tal que lo hace digno de ser permanentemente considerado como una muestra de lo que se debe hacer o de lo que se debe evitar.

Ante la práctica de recurrir a ejemplos en la vida cotidiana, se hace necesario distinguir entre tipos de ejemplos, ya que cualquier hecho, 
acontecimiento o conducta puede ser un buen o mal ejemplo, según se utilice adecuada o inadecuadamente en un determinado contexto, de ahí que no todo hecho, acontecimiento o conducta pueda servir como un buen ejemplo. Debemos preguntarnos entonces, ¿cuándo sucede que algo es considerado como un buen ejemplo?

Antes de continuar, conviene hacer una aclaración que elimine de antemano cualquier confusión en torno a los "buenos o malos ejemplos". La denominación de "buen ejemplo, mal ejemplo" es un tanto ambigua, y por ello son variados los usos y connotaciones que se le atribuyen. Por eso es preciso aclarar que en este trabajo, cuando hablo de buenos o malos ejemplos, lo hago en términos de adecuación, para indicar el grado de éxito que tiene el ejemplo cuando es aplicado al caso en cuestión y no en el sentido moral del término.

Al usar dicho adjetivo no estoy hablando de ejemplos que intrínsecamente entrañen bondad o maldad en sus contenidos, ya que dichas valoraciones morales están fuera de la discusión que aquí se propone. En este contexto, un "buen" ejemplo es simplemente un ejemplo que resulta exitoso para explicar los propósitos que se plantea, en contraposición a un "mal ejemplo", que no es adecuado ni exitoso para explicar lo que se propone. ${ }^{15}$

En este trabajo, cuando hablo de un ejemplo bueno o malo estoy circunscribiendo nuestra atención a la "referencia" del hecho (y no a la valoración del contenido material del mismo); dicha referencia puede ser adecuada o exitosa, tomando en cuenta los fines que persigue, es decir, lo que pretende mostrar con la referencia del hecho; en ese sentido, diríamos " $x$ es un buen ejemplo", que debe entenderse como "la referencia que hacemos de que $x$ es adecuada y exitosa para demostrar lo que pretendemos". 16

En el ámbito judicial y como resultado de su principal función, los tribunales de un sistema judicial resuelven las controversias que las

15 En ese sentido, cualquier hecho, acontecimiento o conducta puede ser tomado como ejemplo, pero una cosa es el hecho en sí mismo y otra es la referencia que se hace del mismo hecho; así, debemos distinguir entre el hecho y la referencia que se hace del hecho.

16 Pensemos en un enunciado ordinario como el siguiente: un "porsche" es un buen ejemplo de un automóvil deportivo; en cambio, un "tsuru" es un mal ejemplo de un automóvil deportivo. 
partes en conflicto les plantean para su resolución como los órganos que institucionalmente están encargados de ello. ${ }^{17}$ Además de este hecho, parece ser una tendencia general en los distintos sistemas jurídicos que en la ejecución de su función principal, los tribunales presten atención a la forma en la que se han resuelto controversias similares previamente a las que ellos se enfrentan en otros tribunales.

La práctica de los tribunales de recurrir a pautas comunicadas mediante el ejemplo (resoluciones anteriores propias o ajenas) está ampliamente difundida y se observa tanto en los sistemas jurídicos en donde dicha práctica está institucionalizada, como en aquellos en los que no hay una obligación legal de llevarla a cabo.

Detrás de este fenómeno se encuentra el hecho de que en la elección de seguir un determinado ejemplo intervienen algunas consideraciones del tribunal como órgano judicial que es parte de un sistema jurídico, consideraciones como la adecuación de semejanza (si se trata de un buen ejemplo) y el origen de dicho ejemplo, es decir, el tribunal que lo emitió. Esto quiere decir que la elección de los tribunales de seguir un determinado ejemplo no es una elección aleatoria o subjetiva, sino motivada, razonada y evaluada a partir de diferentes elementos, principalmente dos muy importantes en la decisión: la adecuación y el origen del ejemplo.

Esta idea se ilustra bien en el muy conocido ejemplo de Hart sobre la enseñanza mediante el ejemplo: "Antes de ir a la iglesia un padre dice a su hijo: «Todos los hombres y niños varones deben descubrirse al entrar a la iglesia». Otro padre, descubriéndose al entrar a la iglesia, dice a su hijo: «Mira, esto es lo que debe hacerse en estas ocasiones»".18

Posiblemente el niño cuenta con una idea general acerca de lo que se debe y no se debe hacer en ciertos lugares, pero parece ser que la principal motivación de su conducta es el ejemplo de su padre; en el lugar en el que el niño se encuentra y en su vida cotidiana está

17 Aunque es una práctica especialmente marcada en el ámbito judicial, Lamond señala que, en los escenarios institucionales, los agentes facultados para tomar decisiones suelen sujetarse a lo que se ha hecho en el pasado, independientemente de si consideran que la decisión original fue correcta. Lamond, Grant, "Precedent and Analogy in Legal Reasoning", Stanford Encyclopedia of Philosophy, 2006, p. 23, consultable en: http://plato.stanford.edu/entries/legal-reas-prec/, cit., p. 2.

18 Hart, El concepto de derecho, cit., pp. 155 y 156. 
expuesto a muchas otras conductas de personas que podría imitar, ejemplos que podría seguir, pero ninguno de ellos tiene la fuerza e importancia que tiene el ejemplo del padre al hijo.

La fuerza e importancia que tiene la conducta del padre sobre el hijo se debe, al menos en parte, a que el padre representa para el hijo una autoridad (posiblemente una de gran importancia), la cual está fuertemente relacionada con una estructura jerárquica implícita en la familia, en la que los padres se sitúan en posición de indicar a los hijos lo que debe hacerse. ${ }^{19}$ Esto significa que algunos ejemplos pueden influir de manera importante para la toma de un determinado curso de acción, pero no cualquier ejemplo, sino un tipo específico, lo que nos remite directamente a la idea de la propiedad de ejemplaridad en el concepto de precedente y el ejemplo dotado de autoridad.

A semejanza del niño en la iglesia, los tribunales actúan según el ejemplo que les presenta el actuar de otros tribunales superiores que han resuelto previamente en casos similares. No es que en ese actuar se haya emitido una regla que explícitamente disponga a los tribunales suscribirla y aplicarla, sino que la actuación del tribunal autorizado respecto de los contenidos sustantivos que suscribió tienen calidad ejemplar para otros. Veamos en qué consiste.

\section{SOBRE LA PROPIEDAD DE EJEMPLARIDAD \\ Y EL RECURSO A LA ANALOGÍA}

Partimos de la idea de que cuando surge una nueva regla de precedente, tiene entre sus objetivos aclarar y determinar con suficiente

19 Es posible que en los casos no jurídicos existan otros elementos de igual importancia a considerar además de la jerarquía existente entre el que despliega una conducta y el que la sigue, pensemos en la experiencia, el conocimiento o la confianza. En contraste, los casos jurídicos parecen conceder centralidad a la estructura jerárquica de las instituciones porque éstas forman parte del sistema en su conjunto y responden a un modelo institucional determinado, independientemente de la persona que desempeñe las funciones u ocupe los cargos. Si bien no descarto la existencia de otros elementos que pueden intervenir en la decisión, no poseen la centralidad de la jerarquía, y todo elemento subjetivo adicional que pudiera advertirse corresponde a una investigación distinta, más allá de los límites de este trabajo, cuyos objetivos son diversos. 
especificidad lo que la norma jurídica general aplicable dejaba indeterminado, esto significa que en el futuro será más fácil y claro para jueces subsecuentes determinar su aplicación concreta. En ese sentido, cuando se presentan escenarios de disputas parcialmente reguladas, esto es, cuando no hay una norma jurídica claramente aplicable o habiendo normas jurídicas parcialmente aplicables no brindan una respuesta concreta al problema planteado (puede ser una regla de precedente), se recurre a herramientas adicionales, como la analogía, en el proceso de balancear las razones dependientes aplicables.

El razonamiento por analogía o analógico es un tipo de razonamiento muy común en la labor judicial, forma parte de la práctica judicial y se emplea cuando se está ante problemas sin resolver del tipo de disputas parcialmente reguladas. ${ }^{20}$ En el razonamiento por analogía, el juez recurre a sentencias previas que contienen reglas que pueden o no ser autoritativas ${ }^{21}$ para él, pero que son, en cambio, buenos ejemplos previos con características semejantes o distintas en un sentido relevante que brindan una guía para resolver el caso presente.

Así, el recurso a la analogía se plantea en los escenarios de disputas parcialmente reguladas, es decir, en los escenarios en los que existe la necesidad de crear una regla de precedente para un pro-

20 En el razonamiento por analogía se busca en el sistema jurídico una base que respalde la solución que se propone, con una fuerza persuasiva inferior que si se tratara de una norma jurídica obligatoria; sin embargo, su racionalidad radica en mostrar que la solución propuesta es "consistente" con el cuerpo jurídico normativo vigente como una extrapolación de dicho cuerpo. MacCormick, Neil, Legal Reasoning and Legal Theory, Oxford, Oxford University Press, 1978, p. 120.

21 Las reglas de precedente a las que se recurre por analogía no necesariamente son autoritativas ni estrictamente aplicables al caso, sino simplemente buenos ejemplos que sirven para el caso en cuestión en algún aspecto relevante, ya que el caso de las reglas de precedente son de clara aplicación deductiva y no requieren analogía. En contraste con esta opinión, Cass Sunstein opina que un precedente puede servir como una regla: cuando gobierna plenamente casos idénticos, o como una analogía, cuando se distingue en, al menos, un aspecto del caso presente, pero que sugiere un principio o política general relevante al caso presente. Sunstein, Cass R., Legal Reasoning and Political Conflict, Nueva York, Oxford University Press, 1998, p. 71. 
blema que carece de respuesta directa y el tribunal autoritativo la utiliza como un recurso - entre otros - en el proceso de balancear razones dependientes e interpretar para arribar a la regla de precedente adecuada. ${ }^{22}$

Al respecto debe decirse una obviedad: ningún caso es idéntico entre sí, ni los hechos identificados en cada uno son idénticos, eso es imposible; sin embargo, para encontrar la analogía se toman en cuenta los aspectos relevantes para la decisión, por lo que la falta de identidad exacta entre los hechos no es obstáculo para encontrar semejanzas o diferencias relevantes que permitan extraer un principio o estándar útil que guíe u oriente la decisión del juez, permitiéndole utilizar ese principio como una de las razones dependientes que considerará en el balance, basándose en el razonamiento acumulado de tribunales previos.

Ahora bien, hemos dicho anteriormente que los tribunales pueden recurrir a buenos ejemplos previos ${ }^{23}$ que presenten semejanzas o diferencias relevantes con el caso que se resuelve para guiarse en su resolución, ejemplos que no necesariamente son reglas de precedente. ${ }^{24}$ Para determinar la aplicación por analogía de una solución previamente dictada, el juez subsecuente habrá de comparar el caso presente con algunos casos pasados que son revisados para determinar si el caso pasado controla, se distingue o puede ser extendido al caso presente. El caso pasado puede contener una opinión, una regla, un estándar o hechos que serán evaluados en cuanto a similitudes y diferencias para identificar la regla o principio aplicable. ${ }^{25}$

Cuando emplea este tipo de razonamiento, el tribunal hace una revisión general de las sentencias pasadas que se han dictado, bus-

22 Por supuesto, la analogía no es una herramienta exclusiva de los tribunales autoritativos, es también empleada por tribunales ordinarios; no obstante, mi interés está en su relación con el concepto de precedente vertical.

23 Emily Sherwin hace también la referencia a "ejemplos" previos en un sentido similar al que yo utilizo. Sherwin, Emily, "A Defense of Analogical Reasoning in Law", University of Chicago Law Review, vol. 66, núm. 5, otoño de 1999, p. 1188.

24 Raz, Joseph, The Authority of Law: Essays on Law and Morality, Oxford, Oxford University Press, 1979, p. 203.

25 Sunstein, op. cit., p. 32. 
cando semejanzas y diferencias con el caso que resuelve y extrae un principio que refleje las semejanzas y diferencias importantes entre ambos que le sirva de base para su propia decisión. ${ }^{26}$ Esto revela que el resultado de esta indagatoria y análisis arrojará un principio orientador que será balanceado junto con otras razones dependientes en el caso, la mera posibilidad de balancear es el indicativo de que la sentencia encontrada no contiene una regla de precedente, que, como hemos visto, es excluyente y no requiere el balance, aunque puede ofrecer los insumos para sentar la regla posteriormente.

En ese sentido, es posible también que cuando el tribunal autoritativo interprete una norma jurídica que regula parcialmente una disputa, acuda y tome en consideración -mediante el razonamiento analógico- las razones que fundamentaron decisiones pasadas semejantes o cercanas a la problemática que resuelve y que al mismo tiempo encuentre adecuadas para el caso particular. Por ejemplo, la semejanza entre casos se encuentra en tanto los argumentos consecuencialistas que justificaron una regla judicial adoptada previamente podrían justificar también una regla similar en el caso presente, no obstante la analogía no obliga a la adopción concreta de una decisión. ${ }^{27}$

Pensemos en una regla que resolvió el caso concreto $A$, cuyos hechos identificados por el tribunal fueron B, C y D. Cualquier tribunal posterior que desee recurrir a esa solución sabe los propósitos y fines que se protegieron en ese caso, y puede determinar si los hechos presentes son similares en un sentido relevante como para adoptar la misma solución. En este caso, es posible que el caso presente $P$, muestre los hechos B y C solamente, o bien, los hechos B, C y E; en ambos casos, se confía en la semejanza entre los hechos que el tribunal considera relevantes para su resultado.

La regla original del caso $A$ sentó la regla $X$ con los hechos B, C y D. Una regla posterior en el caso $P$ sentó la regla $X$ con los hechos B y C. Una regla posterior en el caso $Q$ sentó la regla $X$ con los hechos B, C y E.

27 MacCormick, Legal Reasoning..., cit., p. 186. 
La analogía entre ambos casos con el original puede radicar en la similitud respecto de algunos aspectos importantes solamente y sirve para justificar una solución específica del tribunal en ejercicio de su discreción, proporcionándole a su solución mayor sustento, al considerar que fue la mejor regla a la que pudo haber arribado en el caso concreto. La relevancia de las similitudes puede determinarse atendiendo a los propósitos y racionalidad de la regla original, llegando así a la conclusión de que si una regla previa promueve ciertos propósitos y protege ciertos valores, entonces la razón ahí sostenida es suficientemente buena para justificar otra regla, con una similitud derivada. ${ }^{28}$

En el razonamiento judicial, acudir a la analogía es recurrir, principalmente, a un buen ejemplo previo. Se trata de razonar mediante ejemplos cuya fuerza es distinta a la fuerza del precedente, al tratarse de un elemento que lo compone y que ha de tomarse en consideración junto con otros elementos en el razonamiento junto con los grados de adecuación según qué tan exitosa es para justificar un resultado. El concepto de precedente tiene como propiedad la calidad de ejemplaridad de sus reglas que se identifica en su dimensión de “creación", mientras que la dimensión de "aplicación" de estas reglas se identifica con la analogía.

En ese sentido, analogía y calidad de ejemplaridad son conceptos íntimamente relacionados en el de precedente, pues se trata de una sola propiedad que se materializa de una forma u otra, según estemos hablando del momento de creación del precedente o del momento de su uso y aplicación. En virtud de lo anterior, se entenderá según estemos hablando de uno u otro momento.

28 Raz, The Authority of Law..., cit., pp. 203 y 205. En términos de Lamond, la justificación más contundente de este tipo de razonamiento radica en la posibilidad de replicar las soluciones, lo cual favorece la coherencia. Lamond, op. cit., p. 23. Esta postura es muy similar a la sostenida por Raz y Dickson; sin embargo, no existe consenso entre los teóricos acerca de si hay una justificación estrictamente lógica que sustente esta práctica, entre ellos, Cass R. Sunstein, Larry Alexander, Emily Sherwin y Scott Brewer; este último autor ofrece una explicación de este tipo en "Exemplary Reasoning: Semantics, Pragmatics, and the Rational Force of Legal Argument by Analogy", Harvard Law Review, vol. 109, núm. 5, 1996. 
Nótese que en los casos $P$ y $Q$ antes referidos, recurrir a la regla establecida en el caso original $A$ tiene que ver principalmente con la idoneidad de los contenidos de la regla, que es un parámetro de identificación en el proceso de razonamiento por analogía. Esto quiere decir que el caso $A$ del que estamos hablando no es necesariamente uno que contenga reglas de precedente; de ahí que se identifique el hecho de que el razonamiento analógico está asociado al razonamiento judicial en general, aunque se vincula de manera particular con el concepto de precedente.

Mientras que la analogía es solamente una de las formas de interpretar en el derecho a través de buscar las semejanzas sustantivas entre casos, la calidad de ejemplaridad del precedente trasciende a este ejercicio, y debe advertirse que esta calidad concurre en el precedente junto con otros elementos que explican conjuntamente su naturaleza.

Las reglas de precedente regulan mediante el ejemplo la conducta futura, ya que el tribunal futuro habrá de buscar en la experiencia judicial previa acumulada, elementos de solución, lo cual ocurre gracias al razonamiento analógico. Así, la analogía opera como una especie de "filtro de búsqueda", a través del cual los jueces pueden recuperar los ejemplos previos relevantes para el caso que resuelven. En ese sentido, el razonamiento por analogía es simplemente un razonamiento a partir de buenos ejemplos, pero un precedente es más que solamente un buen ejemplo, puede incluso no ser el mejor ejemplo, pero reúne otras cualidades necesarias.

Pensar estas dos dimensiones según el momento de aplicación facilita la comprensión de esta propiedad. Así, tenemos el momento de creación del precedente, emanado del tribunal autoritativo, y el momento de aplicación o uso posterior del precedente, relacionado con otros tribunales. En el momento de creación del precedente, el recurso a la analogía es uno de los elementos que se combina con otros tantos que estamos estudiando a fin de allegarse de insumos, balancear las razones y configurar la regla de precedente, mientras que en el momento de aplicación, la analogía es un criterio de búsqueda para identificar buenos ejemplos, entre los que pueden figurar reglas de precedente; no obstante, la decisión de aplicar estas reglas responde a otras razones. 
En otras palabras, el razonamiento analógico es una forma de razonar en sede judicial, pero debemos distinguir entre el uso de este razonamiento como tribunal autorizado para sentar una regla de precedente, en cuyo caso la analogía y las razones encontradas en buenos ejemplos previos es solamente uno de los elementos a considerar en el balance de razones que intervienen al sentar la regla de precedente, $y$, por otra parte, el uso de este razonamiento como tribunal ordinario (no autorizado) al que se recurre para resolver según la experiencia previa siguiendo un buen ejemplo (simple analogía) en casos semejantes o aplicar un buen ejemplo dotado de autoridad (precedente). Para determinar la aplicación de reglas de precedente, la analogía por sí misma no es suficiente, pues convergen otros elementos, digamos, la calidad de regla prescriptiva y autoritativa de origen jurisdiccional y posición jerárquica.

Evidentemente, al recurrir a la analogía, el tribunal ordinario está en busca de aplicaciones exitosas de buenas razones de segundo orden o de explicaciones cercanas en algún aspecto relevante que le permitan suscribir y trasladar a su caso esas razones. En todo caso, esta dualidad: creación-calidad de ejemplaridad, aplicación-analogía, explica una propiedad necesaria del concepto de precedente que muestra estas dimensiones a través de las cuales se entiende.

Ahora bien, la práctica del razonamiento analógico favorece la perspectiva de diversos operadores jurídicos que toman decisiones con base en un cuerpo nutrido y diverso de materiales jurídicos que conserva en su interior diversas posturas, por lo que es razonable que dicho escenario genere un amplio espacio para el desacuerdo. ${ }^{29}$ No obstante, se puede considerar que las decisiones que emplean analogía ofrecen a su favor un elemento de permisibilidad en el marco del sistema jurídico de que se trate. ${ }^{30}$

29 Lamond, op. cit., pp. 19 y 23.

30 MacCormick otorga un lugar más preeminente a los argumentos por analogía o principio como proveedores de soporte jurídico para las decisiones novedosas como una "condición necesaria" de su permisibilidad. No abordaré sobre este punto, pero cabe decir que en el marco de la explicación normativo-descriptiva que ofrece el autor, los argumentos de analogía o principio están vinculados con la coherencia de principio global del sistema jurídico, que es distinta de la coherencia aquí suscrita. MacCormick, Legal Reasoning..., cit., p. 187. 
En ese sentido, recurrir a la analogía afianza los propósitos ya protegidos por reglas jurídicas previas en casos concretos y promueve la coherencia de esos propósitos en partes específicas del derecho, es decir, la coherencia local, en tanto se sujeta a una regla ya establecida, apoyando sus resultados. ${ }^{31}$

\section{EL EJEMPLO DOTADO DE AUTORIDAD}

Acentuando el carácter distintivo del precedente, en casi todas las sociedades se observa la práctica de resolver las controversias jurídicas atendiendo a la forma en que el problema fue antes resuelto, confiando en la experiencia previa y atendiendo al carácter ejemplar de las reglas a través de la analogía. Es importante notar, sin embargo, que esta práctica, sumamente extendida, de actuar mediante el ejemplo se lleva a cabo selectivamente.

Siguiendo esa línea, los tribunales de los diferentes sistemas jurídicos resuelven las controversias que son sometidas a su conocimiento aplicando las reglas jurídicas establecidas con anterioridad en ese sistema, así como las soluciones que en sentencias previas, tribunales autorizados establecieron para casos similares, tratando las reglas autoritativas dictadas por dichos tribunales como ejemplos a seguir, estuviera o no establecida formalmente la obligación de los tribunales de seguir precedentes.

Tengamos en cuenta que el hecho de que se trate de una resolución adecuada, dígase "buen ejemplo", es una característica necesaria, pero no es la única que posee una resolución judicial para ser considerada como ejemplo a seguir. En ese sentido, cabe preguntarnos ¿qué otro elemento, entonces, distingue a un buen ejemplo de sentencia judicial?, ¿qué es lo que hace que la regla contenida en una resolución y no en otra sea tratada como ejemplo autoritativo para un determinado tribunal?

31 Raz, The Authority of Law..., cit., p. 206. Esta postura, sin embargo, no es uniformemente compartida entre los teóricos, pues hay quienes lo consideran un razonamiento inferior al razonamiento moral ordinario del juez. Alexander, Larry, "Bad Beginnings", University of Pennsylvania Law Review, vol. 145, núm. 1, 1996, p. 57. 
La reflexión anterior nos conduce a centrar la atención sólo en los casos en los que un tribunal tiene la obligación de seguir un buen ejemplo predominante. En tales casos, el hecho de "tener la obligación" implica, como se ha visto, que existe una regla que es autoritativa para sus destinatarios, que sirve como razón para la acción y reemplaza otras razones. Es así como en tal contexto convergen la calidad autoritativa de la regla contenida en la resolución judicial, ${ }^{32}$ la calidad de ejemplaridad de la regla y la jerarquía judicial. Ninguno de estos elementos por sí mismo explica plenamente la segunda condición necesaria del concepto de precedente judicial, sino la combinación e interacción que se presenta entre ellos.

Es claro que para que una regla judicial se distinga de otras reglas judiciales - posiblemente igualmente valiosas - es necesario que muestre un elemento adicional que la haga preferible sobre otras. Esto significa que la regla judicial es un buen ejemplo, cuyo contenido es adecuado para su aplicación en otros casos semejantes, pero esta característica no es suficiente y no revela cómo se distingue de otros posibles buenos ejemplos.

Como la descripción anterior muestra, no es solamente el contenido ejemplar de la propia regla judicial el que le proporciona la calidad autoritativa, no es la resolución por sí misma la que nace con autoridad, ni tampoco es la resolución la que ocupa una posición dentro de la estructura jerárquica y que en consecuencia "obliga". Si la cualidad autoritativa de la que hablamos se debe no sólo al propio contenido de la regla judicial, el único lugar de donde dicha cualidad puede provenir es del órgano que emite la resolución. ${ }^{33}$

32 En adelante, regla judicial.

33 Como en el ejemplo de Hart, parece ser que lo que el niño imita no es solamente la conducta valiosa del padre; de ser así, el niño dispondría de los buenos ejemplos de otras personas; sin embargo, a pesar de tener disponibles varios buenos ejemplos, el ejemplo del padre tiene un elemento adicional que le distingue, con la fuerza para descartar a los demás y que dada la estructura en la que se presenta, goza de una deferencia natural: su origen. Claro es que el padre puede proporcionar buenos y malos ejemplos al hijo, pero la función natural asociada a esa figura es la de proporcionar buenos ejemplos, aunque ocasionalmente se equivoque y aunque, en ocasiones, haya padres que no comprendan su función y no actúen en consecuencia. 
Hemos hablado de la calidad de ejemplaridad y los buenos ejemplos en el razonamiento judicial, de modo que requerimos concentrarnos ahora en la propiedad autoritativa de la regla que es simultáneamente un buen ejemplo.

Así pues, ¿qué es un ejemplo dotado de autoridad? Como antes vimos, ordinariamente las indicaciones de una autoridad tienen una importancia distintiva en nuestras vidas; mostramos una deferencia especial hacia ellas en comparación con las indicaciones de cualquier otra fuente. A semejanza del caso del padre en la iglesia, los tribunales siguen ejemplos - aunque no cualquier ejemplo ni todos los ejemplos-, si bien no en todos los casos y sólo lo hacen en determinadas circunstancias (en algunos sistemas jurídicos, incluso, eligen seguirlos).

Esclarecer el asunto de los ejemplos dotados de autoridad es una condición necesaria para la comprensión plena del concepto de precedente. A pesar de que en la práctica cotidiana los tribunales pueden encontrar buenos ejemplos a seguir en las resoluciones de cualquier otro tribunal, no cualquier tribunal emite resoluciones cuyas reglas judiciales revistan autoridad para otros tribunales.

Esto implica que el tribunal $X$ puede considerar la resolución del tribunal $Y$ adecuada para el caso que ahora se encuentra resolviendo y, por lo tanto, aplicar por elección la regla establecida por $Y$ para resolver el caso que le ocupa, aunque $Y$ es su homólogo y no representa ningún tipo de autoridad para él. En este escenario, $X$ pudo libremente seguir o no el ejemplo de $Y$ o cualquier otro tribunal semejante para resolver; no obstante, $X$ no tuvo más razón para seguir el ejemplo de $Y$ que la adecuación de la solución de $Y$ a su caso, es decir, el hecho de que se trataba de un buen ejemplo. ${ }^{34}$

34 Esta situación se aprecia en la cada vez más popular práctica de algunos tribunales de revisar y recurrir a las resoluciones de algunos tribunales de jurisdicciones extranjeras (la así llamada fertilización jurisprudencial) que han enfrentado y resuelto en el pasado controversias similares a los que ellos se enfrentan en el presente, para documentarse, orientar su criterio o seguir su ejemplo al tomar una decisión. En este caso, revisar o considerar resoluciones de tribunales extranjeros es una conducta absolutamente optativa. En algunas ocasiones, los tribunales que recurren a sentencias extranjeras, lo hacen en relación con fallos emitidos por órganos de igual o similar jerarquía, es decir, homólogos; en 
La regla de precedente pretende servir como un ejemplo dotado de autoridad y como tal, tener una posición especial para los tribunales en relación con otros ejemplos al tener autoridad práctica ${ }^{35}$ (proporciona razones para actuar) y reunir al mismo tiempo las características de una regla autoritativa: ${ }^{36} a$ ) la tesis de la dependencia; $b$ ) la tesis normal de justificación, y $c$ ) la tesis de la exclusividad.

Esto quiere decir que el precedente no es solamente un buen ejemplo, sino también una regla dotada de autoridad, porque proporciona una respuesta a un problema específico, basándose en las $\mathrm{RD}^{37}$ pertinentes; por ello los sujetos a ella están justificados al obedecerla, pues es más probable que acierten en su actuar si siguen la regla; además, su compromiso de obedecer la regla los previene de efectuar un balance de razones: la regla de precedente es su razón para actuar. En ese sentido, seguir la regla de precedente es la forma adecuada de actuación judicial, independientemente de si es el mejor ejemplo (justificación independiente de contenido) de entre los buenos ejemplos disponibles.

Las reflexiones previas muestran que no es solamente el contenido de la resolución del tribunal lo que hace de ella un ejemplo

estos casos llama la atención que no existe de por medio una relación institucional ni jerárquica entre tribunales, por lo que hay otros factores que explican la persuasión que tales resoluciones pueden llegar a tener en otras jurisdicciones. Por una parte, es posible que la persuasión que ejercen ciertos tribunales y sus fallos, en sistemas jurídicos extranjeros, tenga que ver con el órgano que la emite, o bien con la resolución en sí misma. En cualquier caso, algunos advierten en esta práctica la posibilidad de otras formas de explicar el precedente, no obstante no debemos perder de vista que la elección de sujetarse a alguna resolución extranjera, conserva el carácter optativo para el tribunal receptor, de modo que no podríamos decir que se trata de un precedente en estricto sentido.

35 Lamond, op. cit., p. 3. Si bien Lamond difiere acerca del tratamiento que mejor explica la naturaleza del precedente, coincide en afirmar la autoridad práctica del precedente, además de poner énfasis en lo que el tribunal hizo por encima de lo que dijo.

36 Entendida como un criterio general y permanente que pretende guiar la conducta. Véase "regla", en Bix, Brian H., Diccionario de teoría jurídica, trad. de Enrique Rodríguez Trujano y Pedro Villarreal Lizárraga, México, UNAM, Instituto de Investigaciones Jurídicas, 2009, p. 238.

37 Razones dependientes. 
autoritativo para otros tribunales. ${ }^{38}$ En un sentido general, podemos afirmar que no todas las reglas autoritativas son ejemplos para semejantes, ni todos los buenos ejemplos son reglas autoritativas. En un sentido particular - hablando de precedente-, no todas las reglas autoritativas tienen el alcance para fungir como ejemplos de otros tribunales semejantes e inferiores; así, aunque cualquier sentencia puede ser usada como ejemplo, no cualquier sentencia es una regla autoritativa (para tribunales semejantes e inferiores) con alcance más allá del caso que resolvió.

Ahora bien, es claro que los hechos de un caso pasado no serán iguales a los hechos de otro caso actual, pero la aplicación del precedente no demanda una identidad absoluta — de ser así, el precedente no podría existir-; en cambio, la forma de determinar cuándo aplica un precedente requiere determinar las semejanzas relevantes del caso actual con el precedente a través de algún criterio que permita identificar las semejanzas que son importantes de las que podemos ignorar. ${ }^{39}$

Asimismo, un sistema de reglas de precedente autoritativas es congruente con la generación de expectativas, porque se atiende centralmente a las indicaciones de la autoridad y, al ser éstas consistentes, es razonable esperar que las personas sujetas a dicha autoridad se generen expectativas. Si los tribunales no trataran al prece-

38 En la vida cotidiana, parecería casi obvio pensar que un ejemplo dotado de autoridad, uno que debemos seguir, forzosamente, tiene que ser el mejor ejemplo. Del mismo modo, válidamente podemos pensar que un ejemplo autoritativo (para los tribunales) necesariamente tendría que ser el mejor ejemplo, pero no necesariamente es así. Con el tiempo, las resoluciones de los tribunales que siguen un precedente se van agregando a una larga cadena de resoluciones similares que junto con las circunstancias cambiantes de cada caso pueden ir modificando la regla hasta que ésta deje de ser incluso una "buena regla", o incluso es posible que un criterio errado de inicio, siente una regla. En tal caso, es posible que la regla deje de ser una buena regla o nunca haya sido la mejor la regla para los casos a los que se aplica, pero aun así sigue siendo un ejemplo autoritativo que debe seguirse. Es posible, incluso, que existan diferentes grados de adecuación de un ejemplo autoritativo, lo que determine que tan buen ejemplo es una resolución.

39 Schauer, Frederick, "Precedent", Revista en Derecho de Stanford, vol. 39, núm. 571, febrero de 1987, p. 5. 
dente de esta forma, no sería posible que las personas generaran las expectativas de las que aquí se hablan.

Una vez que se ha adoptado una decisión autoritativa, dada su adopción institucional, ésta es susceptible de ser replicada por otros tribunales del sistema jurídico; ${ }^{40}$ no obstante, es importante notar que si bien cualquier resolución previa puede ser reproducida como buen ejemplo, sólo las resoluciones autoritativas perdurarán y se afianzarán con el tiempo, y sólo éstas serán consistentemente replicadas: nuevamente, esta situación se deriva de la calidad autoritativa de la regla de precedente.

El argumento de que es deseable dar a los tribunales el poder de crear derecho para actualizarlo, mejorarlo y complementarlo, ${ }^{41} \mathrm{se}$ explica igualmente a través de la autoridad y la tesis de la justificación normal, pues se está justificado a seguir las reglas de la autoridad en tanto que es más probable que, en su calidad de autoridad, elija las razones más adecuadas para guiarnos, que si cada uno trata de decidirlo por su cuenta; así, la constante creación del derecho y la conciencia de esa posibilidad es posible gracias a la noción y al papel de la autoridad en el derecho.

\section{LA REGLA DE PRECEDENTE COMO EJEMPLO AUTORITATIVO PARA LA AUTORIDAD}

La segunda propiedad necesaria del concepto de precedente apunta a explicar la pretensión de regular mediante el ejemplo la conducta de sus destinatarios. En los siguientes párrafos intentaré explicar —desde la teoría de la autoridad- cómo funcionan las directivas autoritativas entre las propias autoridades; en este caso, tribunales y otros funcionarios (que son los otros destinatarios de la regla de precedente), lo cual requiere de un análisis diferenciado.

A partir de los conceptos e ideas antes explicados, relativos a la tesis de la autoridad y acerca de las propiedades necesarias del precedente, podemos profundizar en el estudio de la regla de prece-

40

Lamond, op. cit., p. 17.

41 Ibidem, p. 18.

Problema. Anuario de Filosofía y Teoría del Derecho

Núm. 12, enero-diciembre de 2018, pp. 199-238 
dente entre autoridades, con la intención de obtener una comprensión de la misma, de la manera más fiel posible a la forma en que es entendida por aquellas autoridades que lo aplican.

Ayudémonos del siguiente ejemplo a efecto de contrastar el enfoque del particular con el de la propia autoridad judicial. Supongamos que el tribunal ordinario $A$ emitió sentencia en el caso $X$ y que el actor en dicho proceso judicial no comprendió plenamente los términos de la misma, así que se debate acerca de qué hacer al respecto. Ordinariamente, el actor recurriría a un balance de razones de primer orden, pero en el caso dispone de razones de segundo orden aplicables; esto significa que existen reglas jurídicas procesales aplicables que reemplazan las posibles razones dependientes.

Para determinar qué curso de acción tomar respecto de la sentencia dudosa, el actor recurre a las razones excluyentes aplicables, que contemplan tanto la legislación como los precedentes. Así, resulta que la legislación no proporciona una respuesta a la necesidad del actor, pues no contempla la figura de aclaración de sentencia, pero no obstante el silencio de la legislación, hay un precedente que proporciona una respuesta al cuestionamiento.

La existencia de un precedente que cubre la situación de hecho del actor es una razón excluyente para actuar en consecuencia, ya que le proporciona la respuesta correcta por adelantado, pues seguramente cumplirá mejor con sus razones dependientes (las razones que aplican al actor) si atiende lo que dice la regla en lugar de seguir su propio criterio, además de que le previene de reevaluar constantemente sus acciones con base en razones de primer orden. En este caso, el precedente existente indica al actor que puede promover una aclaración de sentencia, aunque la legislación aplicable no contemple expresamente dicho instrumento procesal.

Ahora bien, volvamos al ejemplo previamente utilizado de aclaración de sentencia, sólo que en esta ocasión enfoquemos el problema desde la óptica del tribunal ordinario para el cual dicho precedente es una regla autoritativa que ha sido comunicada mediante el ejemplo.

Supongamos nuevamente que el tribunal ordinario $A$ emitió sentencia en el caso $X$ y que el actor en dicho proceso judicial no comprendió plenamente los términos de la misma, así que promueve un escrito en el que solicita al tribunal ordinario $A$ que aclare ciertas 
partes de la sentencia. Al respecto, es importante mencionar que la legislación procesal aplicable en la jurisdicción de $A$ no contempla la figura de aclaración de sentencia.

En circunstancias normales, ante la ausencia de un precedente que regule el hecho concreto, el tribunal ordinario $A$ tendría que efectuar el balance de razones jurídicas aplicables al caso, considerando posiblemente algunas como las siguientes: que la solicitud planteada por el actor no está contemplada por la legislación procesal vigente, que toda promoción efectuada por las partes debe recibir una respuesta de la autoridad, que la autoridad jurisdiccional no debe ir más allá de los límites establecidos para su actuación en la ley, que no efectuar dicha aclaración podría ser considerado como denegación de justicia, etcétera.

La existencia de un precedente en la materia, sin embargo, proporciona al tribunal ordinario $A$ una razón —de segundo ordenpara no actuar de acuerdo con el balance ordinario de razones; así, dicha regla de precedente media entre el tribunal $A$ y la respuesta correcta. En este caso, existe un precedente sobre el tema específico que enfrenta el tribunal ordinario $A^{42}$

El precedente de rubro "Aclaración de sentencia", con que cuenta el tribunal ordinario $A$, es una razón excluyente para no entrar al balance de razones que, en otras circunstancias, tendría que abordar, y permite al tribunal tomar la decisión correcta atendiendo a la razón excluyente que aplica al caso; asimismo, le evita al tribunal ordinario $A$ tener que reevaluar la situación cada vez que se le presente una solicitud semejante, pues está actuando con base en el ejemplo autoritativo previo.

Siguiendo esa misma línea, para estar en condiciones de distinguir acerca de las razones que tienen los jueces para resolver en uno u otro sentido, debemos primero situar el contexto de esa autoridad respecto del caso que resuelve. En ese sentido, para conocer la materia prima con la que trabaja un juez ordinario —e incluso cuándo

42 Jurisprudencia 11/2005. Compilación 1997-2012, Jurisprudencia y Tesis en Materia Electoral, México, Tribunal Electoral del Poder Judicial de la Federación, vol. I, Jurisprudencia, pp. 98-100. Rubro: “ACLARACIón DE SENTENCIA. FoRMA PARTE DEL SISTEMA PROCESAL ELECTORAL AUNQUE NO SE DISPONGA EXPRESAMENTE”. 
este juez recurre a las RD o cuándo de hecho tiene RE- es necesario identificar el tipo de escenario ante el que se encuentra, ya que de ello dependerá el tipo de razones que éste emplee en su razonamiento.

Así, los escenarios centrales que debemos distinguir son dos:

1) Aquel escenario que se presenta cuando el derecho está determinado. Recordemos que la tesis de la autoridad del derecho explica que la forma ordinaria de resolver conflictos entre razones de primer orden es a través del balance de esas razones. Los cursos de acción en los que intervienen razones de primer orden y razones de segundo orden se deciden porque las razones de segundo orden reemplazan las razones de primer orden, al elegir alguna(s) de ellas.

Tal como ocurre en el ejemplo del precedente "Aclaración de sentencia", cuando el tribunal ordinario ha de resolver un caso, su misión es trabajar con razones excluyentes de segundo orden, en la medida en la que éstas regulen el caso que resuelve. Cuando hay razones de segundo orden, significa que el tribunal ha verificado que existen normas jurídicas que regulan directamente el tema controvertido en el caso que se resuelve y, por lo tanto, reemplazan a las demás razones aplicables de primer orden, en lo que al tema se refiere.

De este modo, cuando un juez se encuentra ante un escenario en el que el derecho está determinado, su labor consiste en asignar la respuesta adecuada que el derecho proporciona a la situación que se plantea. Sea por legislación o por precedente, el material jurídico existente brinda una respuesta clara y directa al problema, de tal suerte que la norma jurídica aplicable (reúne las tres tesis) tiene autoridad legítima y se aplica al caso; esto significa que funciona como una razón de segundo orden para este juez, al proporcionarle la solución por adelantado, y con ello le permite excluir el balance de otras posibles razones de primer orden. ${ }^{43}$

43 Una explicación semejante, en un contexto más amplio, es proporcionada por MacCormick, quien sostiene que la argumentación jurídica siempre procede sobre la base de un argumento de autoridad; ésta deja de lado cualquier tipo de razonamiento "todos los elementos considerados", es decir, que considera las razones de primer orden del caso, pues cuando se apela al derecho, no son 
Ante la ausencia de la regla de precedente, un tribunal ordinario se vería en la necesidad de analizar cada vez que se le presentara un caso, los méritos particulares del mismo a través de sus razones de primer orden. No obstante, eso es precisamente lo que la existencia del precedente facilita: evita que el tribunal ordinario reevalúe constantemente los méritos de cada caso similar (con base en razones de primer y segundo orden), pues parte de su trabajo es fungir como una respuesta adelantada a cuestionamientos específicos.

$\mathrm{Al}$ hablar de un tribunal que resuelve una controversia, estamos dando por sentado que dicho tribunal es una autoridad dentro del sistema jurídico, aun cuando se trate de un tribunal ordinario; ${ }^{44}$ que las sentencias de dicho tribunal son autoritativas y tienen carácter excluyente para las partes involucradas en juicio; que dada la labor que tienen asignada, los tribunales trabajan ordinariamente en este primer escenario con razones de segundo orden para arribar a una solución.

2) En contrapartida, está un segundo escenario que puede enfrentar el juez: aquel que se presenta cuando el derecho está parcialmente determinado o indeterminado; esto es, que habiendo alguna(s) disposición(es) general(es) aplicable(s) al caso concreto, ésta es demasiado amplia, general o incompleta, de tal forma que no proporciona una respuesta clara y suficientemente determinada al problema jurídico que se plantea. 0 bien, cuando el derecho emplea en su formulación conceptos vagos - que no permiten identificar cuál sería la afirmación adecuada respecto de su aplicaciónocasionando que no haya forma de saber las dimensiones y límites reales de su contenido y alcance, sino hasta después de la determinación hecha por el juez.

La posibilidad de encontrarse con casos en los que el derecho sea parcialmente determinado es constante, aunque si bien es cierto,

considerados todos los elementos, en su lugar se cumple con lo que exige la norma jurídica. MacCormick, Neil, "Argumentation and Interpretation in Law", Ratio Juris. An International Journal of Jurisprudence and Philosophy of Law, vol. 6, núm. 1, marzo de 1993, pp. 18 y 19.

$44 \mathrm{Al}$ referirme a un tribunal ordinario, lo hago pensando en cualquier tribunal que no tiene una posición de instancia final en la jerarquía judicial en relación con otros tribunales y cuyas sentencias tienen un alcance limitado. 
no se presenta respecto de todo el material jurídico normativo, sino sólo en algunas partes; por ejemplo, cuando se emplean expresiones vagas, tales como "peligro razonable", "trato adecuado", "debido cuidado", "reproducción sustancial de una obra", etcétera.

De cualquier forma -independientemente de la severidad de la indeterminación que exista-, en el escenario 2, esto es, cuando el derecho está parcialmente determinado o indeterminado, el juez inevitablemente debe recurrir directamente a razones dependientes. Surge entonces la pregunta, ¿cómo ocurre esto, si acabo de decir que "ordinariamente" el juez trabaja con razones excluyentes y no con razones dependientes?

Pues bien, en ocasiones el derecho está parcialmente determinado o indeterminado, lo que significa que existen normas jurídicas - legislación y/o precedentes autoritativos- que si bien regulan el objeto de la disputa jurídica, que tratan sobre el núcleo de la disputa o sobre temas o aspectos periféricos a ella, resultan demasiado amplias para aplicarlas directamente; o son tan generales que realmente no proporcionan guía en algún sentido; o incluso son incompletas, de tal forma que no contemplan ciertos aspectos específicos de una cuestión jurídicamente regulada, que resultan novedosos y por ello nunca antes cuestionados ni incorporados al derecho; o simplemente que su redacción es oscura al incorporar términos afectados de vaguedad.

En este segundo escenario, decir que el derecho está parcialmente determinado - regulación deficiente, redactada en términos demasiado amplios, de manera muy general, incompleta o sobrada- equivale a decir que no proporciona una respuesta concreta al problema planteado, por lo cual, si no existe una respuesta por adelantado que solucione el problema, entonces el juez no tiene razones excluyentes para decidir, e inevitablemente debe volver al balance y análisis de razones aplicables de primer orden o razones dependientes (RD).

Puede suceder que aun cuando el derecho regule algún aspecto de la situación de hecho que se plantea en litigio, dicha regulación sea insuficiente, en el sentido de que el material jurídico existente no proporciona una respuesta concreta al problema que se plantea al juez que resuelve. Cuando esto sucede, no es posible hablar de que 
el tribunal como autoridad judicial tenga verdaderamente una RE para decidir, toda vez que una RE es una razón para la acción con el peso suficiente para excluir otras RD aplicables al caso.

Para hablar de una RE, la regla aplicable tendría, en principio, que proporcionar una solución adecuada basada en las RD del caso, haber sido elegida y aplicada previamente por la autoridad judicial autoritativa para convertirse en RE que respondiera al problema, lo cual no sucede.

Consideremos el siguiente caso. En la sentencia 5855 de 2011,45 el Tribunal Supremo Español se enfrentó a un caso en el que el derecho estaba parcialmente regulado cuando se sometió a su consideración un recurso de casación en contra de la sentencia de apelación 1491/2008, dictada por la Audiencia Provincial de Álava que declaraba el divorcio entre Pura y Maximino.

En el caso se consideraba que a causa de un accidente, Pura quedó en estado de coma vigil desde 2000, sin haber recibido los cuidados y deberes de ayuda por parte del esposo como estipula el matrimonio, de modo que los padres de Pura - habiendo sido nombrados sus tutores legales - interpusieron demanda de divorcio en representación de la hija, acción que les es concedida en apelación. Contra esa resolución, el esposo interpuso recurso de casación.

Se trata de un caso complejo que no tenía una respuesta en la legislación española, ya que si bien se contemplaba que el tutor es representante del incapaz, no había una base legal explícita que le permitiera o prohibiera ejercer las acciones personalísimas - como el matrimonio o divorcio- a nombre de la incapaz. Así, el tribunal debía determinar si la Audiencia actuó conforme a derecho respecto de si los tutores estaban legitimados para ejercer la acción de divorcio, considerando el derecho de la incapaz a una tutela judicial efectiva y el principio de igualdad entre los cónyuges.

El ejemplo planteado muestra con claridad que si bien se tenía material jurídico normativo que regulaba la situación de los incapa-

45 Sentencia consultable en: http://www.poderjudicial.es/search/doAction?ac tion $=$ contentpdf\&databasematch $=$ TS\&reference $=6138614 \&$ links $=\% 221491 / 2008 \%$ $22 \% 20 \% 22625 / 2011 \% 22 \&$ optimize $=20111007 \&$ publicinterface=true, consultada el 6 de abril de 2017. 
ces, lo cierto es que la complejidad de las relaciones humanas puede plantear y planteó un conflicto novedoso para el cual no se tenía una respuesta anticipada. Ante la ausencia de una respuesta jurídica anticipada, el tribunal tiene que recurrir tanto al material normativo aplicable como a los hechos particulares del caso, así como a la interpretación jurídica. En efecto, la ausencia de una respuesta anticipada al problema significa que no hay forma de tratar el material jurídico normativo como razones de segundo orden definitivas, por lo que se debe efectuar el balance de RD para llegar a la solución.

En el caso, el Tribunal Supremo tuvo que considerar y balancear razones de primer orden como las siguientes: $a$ ) si efectivamente la legislación concedía a los representantes legales de la incapaz legitimación para ejercer la acción de divorcio; $b$ ) que la libertad de seguir o no casado es un derecho fundamental; $c$ ) que el divorcio no requiere alegación de causa; $d$ ) que la tutela judicial efectiva permite ejercer las acciones cuya titularidad corresponde al incapacitado por medio del representante legal, incluidas la separación y el divorcio; $e$ ) el tratamiento del divorcio en legislación extranjera; $f$ ) que las acciones de los representantes deben ejercerse en beneficio del tutelado y obedecer a los intereses del incapaz, entre otras.

Finalmente, el Tribunal Supremo desestimó el recurso de casación sobre la sentencia, confirmándola en sus términos, al admitir que, efectivamente, era del interés de la incapaz aprobar la acción de divorcio ejercida por los tutores en estos casos. Vemos entonces que en este escenario, el tribunal no tuvo realmente una RE que le evitara recurrir al balance de RD, por lo cual tuvo que recurrir al balance de RD para determinar la respuesta al caso que se estudiaba -incluidos futuros casos semejantes-, y así sucede cuando se trata de una autoridad judicial jerárquicamente reconocida y autorizada para tales efectos.

Cabe señalar que cuando se trata de una autoridad judicial no autorizada, dicha autoridad debe igualmente dar una solución al problema, aunque no tenga la respuesta concreta en el material jurídico normativo, dada su obligación como autoridad; sin embargo, su solución únicamente tendrá efectos entre las partes y es probable que sea recurrida y llevada a una instancia superior en donde pueda adquirir definitividad — tal como ocurrió en el ejemplo re- 
ferido-y ser resuelta autoritativamente para el caso planteado y otros casos futuros.

Decíamos que dentro de una estructura judicial, ciertos tribunales de mayor jerarquía tienen reservada la función de sentar reglas autoritativas que sirvan como ejemplo para el comportamiento futuro de tribunales inferiores, o incluso, tienen determinado el alcance de sus reglas para los tribunales del mismo rango. Si bien todo tribunal es una autoridad en relación con los particulares, siguiendo la línea de distribución del trabajo y competencias de una jerarquía judicial, es posible advertir qué tribunales son una autoridad para los demás tribunales dentro del orden judicial y, por tanto, a qué tribunales y sentencias autoritativas están sujetos en su actuar.

Aunque toda autoridad judicial tiene pretensiones autoritativas, no toda autoridad judicial está habilitada para que las reglas establecidas en sus sentencias tengan el alcance para obligar a otros tribunales jerárquicamente inferiores. En ese sentido, cada tribunal conoce el alcance de sus propias sentencias, de modo que cuando un tribunal de primera instancia dicta sentencia, lo hace con la intención de resolver el caso concreto y con la pretensión de que sea tratada autoritativamente por las partes en el juicio y cumpla su función de ejemplaridad.

Cuando un tribunal de mayor jerarquía de naturaleza final - digamos un tribunal superior o un tribunal de apelación- dicta sentencia en el caso que se le presenta, lo hace con conocimiento de que la regla que en ella establece está llamada a resolver no sólo el problema planteado en la disputa que resuelve, sino también a servir como ejemplo autoritativo para tribunales inferiores cuando deban resolver problemas similares. ${ }^{46}$

Así pues, lo que sucede cuando un problema jurídico parcialmente regulado llega al conocimiento de la autoridad judicial habilitada es, en términos generales, lo siguiente: una vez realizado el análisis del problema jurídico planteado a su conocimiento, el tribunal procede

46 Me refiero únicamente a otros tribunales, dejando intencionalmente de lado a otras autoridades no judiciales (digamos del ramo ejecutivo y legislativo), dado que la posibilidad de que las reglas de precedente obliguen erga omnes a otros órganos del Estado, además de a los propios órganos judiciales, es una cuestión contingente, no necesaria. 
a revisar minuciosamente el material jurídico existente para determinar qué normas jurídicas son las que regulan el problema, en las cuales fundamentará su sentencia.

Una vez hecho lo anterior, advierte que las normas jurídicas que regulan parcialmente el problema que se estudia son incompletas, sobradas, generales o amplias, de forma tal que no proporcionan una respuesta auténtica al problema; es decir, requieren que la autoridad judicial recurra al balance de RD para tomar la decisión, en el cual ineludiblemente interviene la interpretación. Es así que dada la insuficiencia de las normas jurídicas existentes en el caso concreto (sea legislación o precedentes), no pueden ser tratadas como $\mathrm{RE}$, de modo que en el balance de razones que efectuará la autoridad judicial, las normas jurídicas serán tratadas como razones de primer orden y balanceadas junto con otras razones aplicables a la luz de la interpretación más adecuada.

Siendo así, en adelante, cuando un tribunal ordinario que es parte de una estructura jerárquica dentro de su propio sistema jurídico deba resolver un caso similar, dicho tribunal ordinario ya no tiene que llevar a cabo el balance de razones de segundo orden; no lo necesita, porque dicho balance ya ha sido efectuado con anterioridad por un tribunal autorizado. Lo que ahora le corresponde hacer es seguir el ejemplo autoritativo, esto es, aplicar el precedente que -en el contexto referido - funciona como razón excluyente entre las normas jurídicas aplicables.

Es pertinente, pues, la observación de que el precedente no elimina las razones que sustentan las normas jurídicas aplicables parcialmente determinadas, sino que reemplaza las reglas jurídicas generales de cuya interpretación procede, al ser resultado de una interpretación efectuada en torno a aspectos específicos de dichas reglas aplicables a la luz del problema planteado.

Un análisis más detallado muestra dos elementos detrás de esta afirmación: 1) que la regla de precedente fue emitida por un tribunal que a su vez es una autoridad para el tribunal ordinario, y 2) que la regla de precedente es resultado de un balance de razones de primer orden, pues recordemos que en el caso, el material jurídico aplicable no tiene capacidad excluyente. En ese sentido, una vez identificada la regla aplicable, se efectuó una interpretación a la luz de los méri- 
tos del caso, todo lo cual dio como resultado una regla distinta a las reglas jurídicas existentes hasta el momento, esta vez de segundo orden y vinculada directamente con las particularidades planteadas por las partes.

\section{LA PROYECCIÓN DEL PRECEDENTE}

Ahora bien, esta pretensión de regular la conducta futura de sus destinatarios, a la que me he referido como una condición necesaria del concepto de precedente, bien puede ser identificada como la "proyección del precedente" y se explica de la siguiente manera.

$\mathrm{Si}$ atendemos a los objetivos que primordialmente tiene atribuidos un ejemplo dotado de autoridad o, en otras palabras, el precedente, advertimos que no es casualidad que cada resolución emitida por los órganos jurisdiccionales esté dirigida a asegurar objetivos básicos del sistema jurídico, pero más aún, no es coincidencia que cada decisión judicial se emita considerando el impacto que la misma tendrá dentro del sistema jurídico y las posibles consecuencias que su aplicación generará.

En otras palabras, es imposible que al emitir un fallo, el juez autorizado ignore los efectos que el mismo desencadenará, porque todo juez autorizado es consciente de que al ingresar al sistema jurídico, su sentencia autoritativa engrosará el tejido normativo que permite la coordinación de los diferentes actores de la sociedad Esto implica que su ratio decidendi y obiter dictum continuará o establecerá una nueva línea de razonamiento jurídico que pretende tanto armonizar con el resto de las normas jurídicas que ya son parte del sistema jurídico, primordialmente con las normas fundamentales del mismo, así como avanzar soluciones no contempladas en tales normas. ${ }^{47}$

En el marco de las estructuras judiciales modernas que cuentan con esta institución jurídica, no es posible pensar a la regla de precedente como una regla ordinaria debido a que hay más riqueza en la práctica de lo que el concepto de regla implica. En ese sentido, si

47 Postema, Gerald, "Melody and Law's Mindfulness of Time”, Ratio Juris, vol. 17, núm. 2, junio de 2004, p. 221. 
bien las reglas sirven para regular la conducta, lo cierto es que la naturaleza del precedente no se explica propiamente como una directriz que regula la actuación judicial, sino de una regla con calidad ejemplar cuyo contenido tiene alcance más allá del caso concreto.

Esta condición se entiende mejor cuando nos situamos en el momento en el que se sientan reglas de precedente por primera vez, pues es entonces cuando surge una interesantísima interrogante que debe abordarse como una característica propia de estas reglas. Dicha interrogante gira en torno a la proyección del precedente y cuestiona esencialmente si el ejemplo dotado de autoridad actúa del presente hacia el futuro, o bien, actúa del presente hacia el pasado; la pregunta concreta sería la siguiente: ¿el ejemplo dotado de autoridad se establece hacia el futuro o a la inversa?

Mi apreciación es que la regla de precedente, emanada del órgano con autoridad final, se establece considerando invariablemente su proyección, esto es, la intención implícita de proporcionar una respuesta a disputas jurídicas futuras. Su foco de atención se ubica no sólo en el caso presente, sino también mirando hacia casos futuros. ${ }^{48}$ Al tratarse de una regla autoritativa emanada de un órgano judicial autorizado, desde el momento de su emisión será un ejemplo dotado de autoridad para todos los casos futuros en los que tenga aplicación, por lo que el tribunal conoce de antemano la carga que trae aparejada su sentencia.

No ocurre lo mismo con las reglas autoritativas emanadas de órganos judiciales no autorizados, pues éstos - al igual que los órganos autorizados - están conscientes en todo momento del alcance limitado de su sentencia, así como del impacto y las posibles consecuencias que la misma tendrá dentro del sistema jurídico, las cuales están restringidas únicamente al caso que resuelve.

Siendo así, para que sea posible asegurar la estabilidad del sistema jurídico de que se habla, a través de la función jurisdiccional, es indispensable que los órganos jurisdiccionales de carácter terminal

48 Me refiero únicamente a reglas de precedente, ya que toda sentencia que no provenga de un órgano judicial autorizado está dirigida a solucionar exclusivamente la disputa judicial que fue sometida a su consideración, esto es, el caso presente, por lo que las únicas sentencias que son susceptibles de tener mayor alcance y proyectarse hacia el futuro son las reglas de precedente. 
con autoridad establezcan a través de sus resoluciones las respuestas institucionales definitivas a problemas parcialmente regulados o no regulados en el material jurídico normativo. Esas respuestas institucionales definitivas son concebidas como tales desde su origen, dada la trascendencia que como reglas autoritativas que pretenden ser, tendrán en el sistema jurídico.

Tal proyección es una condición necesaria del concepto de precedente, pues no habría manera de que el juez del presente se comprometiera a seguir el ejemplo autoritativo y aplicar su contenido sustantivo si ignorara esta condición que caracteriza y distingue a ciertas reglas jurisdiccionales autoritativas. La posibilidad misma de que una regla autoritativa de origen jurisdiccional sea aplicada como ejemplo autoritativo de la misma forma que en el pasado se explica no porque así lo disponga el contenido sustantivo de la regla, sino por la calidad de ejemplaridad y proyección que caracteriza al precedente, que se refiere justamente al mayor alcance que esta calidad tiene.

Una explicación alternativa a este planteamiento sugiere que cuando a la autoridad judicial situada en el presente se le presenta un litigio a resolver, busca en el pasado una sentencia que sirva de ejemplo (análoga) para resolver la problemática que se le plantea. Pues bien, si se analiza con detenimiento la explicación anterior, no es, de ninguna manera, diversa del planteamiento principal; antes bien, nos encontramos ante dos perspectivas del mismo asunto, o más precisamente, ante el enfoque que tienen dos autoridades distintas acerca de la misma situación, el de la autoridad que emite el ejemplo autoritativo y el de la autoridad que sigue el ejemplo.

Este fenómeno es observado por Postema, quien advierte que

...lo que un tribunal espera que futuros tribunales (y ciudadanos y abogados que aconsejan ciudadanos) harán y, particularmente, como razonarán es un componente importante, si no es que siempre decisivo en la deliberación del tribunal del presente, quizás tan importante como el razonamiento y decisión de tribunales previos acerca de las deliberaciones de futuros tribunales. ${ }^{49}$

$49 \quad$ Ibidem, p. 217.

Problema. Anuario de Filosofía y Teoría del Derecho

Núm. 12, enero-diciembre de 2018, pp. 199-238 
He afirmado que hablamos en realidad de dos enfoques acerca de la misma situación; no obstante, cabe hacer algunas precisiones. Cuando hablamos del juez que sigue el ejemplo, se nos presentan dos escenarios posibles: $a$ ) el del juez que recurre a resoluciones pasadas para fortalecer y sustentar la sentencia que desea emitir actualmente, que "busca" una resolución análoga en fallos pasados. Tal escenario nos muestra un ejemplo no autoritativo, que aunque se invoca del presente hacia el pasado, no entraña carácter autoritativo ni vinculante; esto es, el juez está en libertad de elegir o no, de entre las resoluciones pasadas, aquella que se ajuste mejor a la situación que se le presenta actualmente. Aunque bien cabe señalar que es una práctica judicial común.

Por otro lado, está el escenario $b$ ), el del juez que conoce la existencia de una serie de resoluciones autoritativas emitidas con anterioridad y que está obligado a seguir en el momento en que se le presente alguna problemática a resolver, cuya respuesta está contenida en alguno de los ejemplos que son autoritativos, o al menos vinculantes para él, establecidos en el pasado. Tal escenario nos muestra un ejemplo autoritativo que se invoca en el presente hacia el pasado, en el que el juez tiene una obligación de acatamiento y no es opcional seguir el ejemplo para el caso específico, sea por la fuerza autoritativa propia del precedente que motiva a hacerlo, o bien, por el elemento vinculante asociado al mismo. En todo caso, el juez en comento es consciente de la proyección y alcance del precedente que suscribe.

Si se observa detenidamente, ninguno de los escenarios expuestos es excluyente o incompatible con la afirmación principal de que el precedente tiene proyección hacia el futuro. La distinción entre la afirmación principal (regla con proyección futura) y las explicaciones alternativas (búsqueda de la regla hacia el pasado) sobre el enfoque adecuado para entender el precedente en este respecto, radica simplemente en la posición desde la que se observa el ejemplo: la posición de la autoridad emisora del precedente o la posición de la autoridad que invoca el precedente o algún ejemplo no autoritativo.

La aplicación del precedente atiende tanto a su uso en las decisiones actuales, pero también su creación atiende a la proyección 
- como la he llamado - hacia el futuro, lo que demanda tratar ciertas decisiones autoritativas actuales como los precedentes de aquellos encargados de tomar decisiones en el futuro, ya que "hoy no es solamente el ayer del mañana; sino también el mañana del ayer". Esta forma de razonar conlleva la responsabilidad espacial de comprometerse con el futuro antes de llegar a él. ${ }^{50}$

Finalmente, hemos de tener en mente que la propiedad de "proyección" de la regla de precedente, entendida como la intención de regular la conducta futura de sus destinatarios, sólo se encuentra y es atribuible a los casos difíciles. En ese sentido, los casos fáciles son casos que llamaré casos regulados, mismos que encuentran solución directa y concreta en el material jurídico-normativo existente, por lo cual no requieren del juez más que una operación deductiva de aplicación. Por otra parte, los casos difíciles, que llamaré casos parcialmente regulados, requieren, invariablemente, de un ejercicio de interpretación por parte del juez para determinar la respuesta correcta al problema planteado, ya que se trata de casos que no encuentran una respuesta concreta en el material jurídico normativo existente.

Las sentencias recaídas a los casos regulados tienen como único objetivo resolver la disputa específica que se plantea en ese caso, y habiendo para ellos una respuesta concreta en las normas jurídicas (sea legislación o precedente), su labor concluye con la identificación y aplicación de esa respuesta normativa. En cambio, en los casos difíciles o parcialmente regulados, el tribunal autorizado tiene que emplear la interpretación para generar la respuesta y solución del problema jurídico planteado; dicha solución es una regla autoritativa nueva - que no existía con anterioridad al caso difícil-, y como tal, esa regla está llamada a dar solución tanto al caso concreto como a casos futuros.

Esa regla autoritativa nueva - habiendo surgido del órgano judicial jerárquicamente autorizado-, desde el momento de su emisión, tiene la pretensión de regular el caso presente y cualquier caso futuro que encuadre en sus términos, pues forma ya parte del dere-

50 Schauer, op. cit., pp. 2 y 3.

Problema. Anuario de Filosofía y Teoría del Derecho

Núm. 12, enero-diciembre de 2018, pp. 199-238 
cho de un sistema jurídico determinado, que habrá de ser aplicado invariablemente a todos las disputas que sean por ella resueltas.

Así, la sentencia de un caso fácil que no requiere de interpretación, no reúne los elementos para convertirse en precedente; esto es, no tiene por objeto regular, mediante el ejemplo, la conducta futura de sus destinatarios, sino solamente resolver el caso que le ocupa y por ello carece de proyección.

\section{CONCLUSIONES}

El precedente es una institución central de los sistemas jurídicos contemporáneos que ha merecido la atención de teóricos en diversos momentos y desde diferentes perspectivas teóricas, buscando aportar una mayor claridad sobre su práctica, o bien, recomendar las técnicas que se juzgan idóneas para crearlo.

Acercarnos a una mejor comprensión del concepto de precedente resulta una labor primordial en el proceso de evaluar nuestras prácticas locales para su eventual reforma y adecuación si así se requiere. He mostrado (pretendidamente) que el análisis conceptual del precedente judicial vertical (como el caso paradigmático) desde la tesis de la autoridad permite revelar características distintivas del concepto que compartimos y proporciona estructura a otras características que explican en conjunto de forma adecuada la naturaleza del precedente judicial.

La ejemplaridad que se exhibe de manera característica en las reglas de precedente lo distingue de otras reglas judiciales autoritativas que no están pensadas para ser tomadas como ejemplos de conducta ni pretenden regular la conducta futura de sus destinatarios, más allá que las partes involucradas en el caso presente. Esta característica no es producto de la calidad autoritativa de las reglas en sí misma, sino una finalidad que asignamos a la práctica del precedente y sin la cual no podría explicarse adecuadamente. Al mismo tiempo, la ejemplaridad del precedente está asociada a su alcance a futuro, que podemos identificar como su proyección. 


\section{REFERENCIAS BIBLIOHEMEROGRÁFICAS}

AlEXANDER, Larry, "Bad Beginnings", University of Pennsylvania Law Review, vol. 145, núm. 1, 1996.

BIX, Brian H., Diccionario de teoría jurídica, trad. de Enrique Rodríguez Trujano y Pedro Villarreal Lizárraga, México, UNAM, Instituto de Investigaciones Jurídicas, 2009.

Bustamante, Thomas, Teoría del precedente judicial. La justificación y la aplicación de reglas jurisprudenciales, trad. de Juan Carlos Panez Solórzano y Brian L. Ragas Solórzano, Lima, Editora y Distribuidora Ediciones Legales E. I. R. L., 2016.

Chiassoni, Pierluigi, "The Philosophy of Precedent: Conceptual Analysis and Rational Reconstruction", en Bustamante, Thomas y Bernal Pulido, Carlos (eds.), On the Philosophy of Precedent. Proceedings of the 24th World Congress of the International Association for Philosophy of Law and Social Philosophy, Beijing, 2009, Stuttgart, Franz Steiner Verlag, Nomos, vol. III, núm. suplementario 133, 2012.

GIUDICE, Michael, “Joseph Raz's Legal Philosophy”, IVR Encyclopedie, 2009, consultado el 9 de noviembre de 2011 en: http://ivrenc.info/index.php?title=Joseph_Raz's_Legal_Philosophy.

HART, H. L. A., El concepto de derecho, trad. de Genaro R. Carrió, Buenos Aires, Abeledo-Perrot, 1961.

Himma, Kenneth, "Reconsidering a Dogma: Conceptual Analysis, the Naturalistic Turn, and Legal Philosophy", HARRIson Ross (ed.), Law and Philosophy. Current Legal Issues, Oxford, Oxford University Press, 2008, SSRN: https://ssrn.com/abstract=952910.

Huerta OchoA, Carla, "Retroactividad en la Constitución", El proceso constituyente mexicano. A 150 años de la Constitución de 1857 y 90 de la Constitución de 1917, México, UNAM, Instituto de Investigaciones Jurídicas, 2007.

Huerta OchoA, Carla, "Sobre la validez temporal de las normas. La retroactividad y ultraactividad de las normas en el sistema jurídico", Problema. Anuario de Filosofía y Teoría del Derecho, núm. 1, 2007. 
LAMond, Grant, "Precedent and Analogy in Legal Reasoning", Stanford Encyclopedia of Philosophy, 2006, consultable en: http:// plato.stanford.edu/entries/legal-reas-prec/.

MAcCormick, Neil, "Argumentation and Interpretation in Law", Ratio Juris. An International Journal of Jurisprudence and Philosophy of Law, vol. 6, núm. 1, marzo de 1993.

MACCoRmick, Neil, Legal Reasoning and Legal Theory, Oxford, Oxford University Press, 1978.

Postema, Gerald, "Melody and Law's Mindfulness of Time", Ratio Juris, vol. 17, núm. 2, junio de 2004.

RAz, Joseph, Between Authority and Interpretation. On the Theory of Law and Practical Reason, Nueva York, Oxford University Press, 2009.

RAZ, Joseph, La ética en el ámbito público, trad. de María Luz Melón, Barcelona, Gedisa, 2001.

RAz, Joseph, The Authority of Law: Essays on Law and Morality, Oxford, Oxford University Press, 1979.

RAz, Joseph, The Morality of Freedom, Nueva York, Oxford University Press, 1986.

Scott Brewer, "Semantics, Pragmatics, and the Rational Force of Legal Argument by Analogy", Harvard Law Review, vol. 109, núm. 5, 1996.

Schauer, Frederick, "Precedent", Revista en Derecho de Stanford, vol. 39, núm. 571, febrero de 1987.

Sherwin, Emily, "A Defense of Analogical Reasoning in Law", University of Chicago Law Review, vol. 66, núm. 5, otoño de 1999.

Sunstein, Cass R., Legal Reasoning and Political Conflict, Nueva York, Oxford University Press, 1998.

THE Internet Encyclopedia of Philosophy, http://www.iep.utm.edu/ concepts/, 20 de junio de 2017.

Vega Gómez, Juan, “El positivismo excluyente de Raz”, Boletín Mexicano de Derecho Comparado, nueva serie, año XXXVII, núm. 110, mayo-agosto de 2004. 